\title{
Achievement of Target Glucose Level among Newly Diagnosed Type 2 Diabetes Mellitus Patients in Public Teaching Hospitals in Addis Ababa, Ethiopia: a retrospective chart review
}

Tigist Workneh Leulseged ( $\nabla$ tigdolly@gmail.com )

Research article

Keywords: Type 2 diabetes mellitus, Glycaemic control, Fasting blood sugar, Retrospective chart review, Logistic Regression, Ethiopia

Posted Date: July 30th, 2021

DOl: https://doi.org/10.21203/rs.3.rs-764257/v1

License: (c) (i) This work is licensed under a Creative Commons Attribution 4.0 International License.

Read Full License 


\section{Abstract \\ Background}

Diabetes is a chronic illness that requires continuous medical care to reach target glycaemic level to prevent complications. Most studies around the world have showed that glycaemic control among type 2 diabetes mellitus (T2DM) patients is poor using measurements taken at one point and including all patients irrespective of the duration of illness. This study aimed to assess achievement of optimal glycaemic control at different points in time in relation to the time of diagnosis and initiation of treatment and to identify associated factors among T2DM patients attending diabetes clinic of public teaching hospitals in Addis Ababa, Ethiopia.

\section{Methods}

A retrospective chart review was conducted from May to July 2018 among randomly selected 685 medical charts of patients who were on follow-up from January, 2013 to December, 2017. Association was assessed using Binary logistic regression, where $95 \%$ Cls for odds ratio and P-values were used for testing significance and interpretation of results.

\section{Results}

The prevalence of optimal glycaemic control among T2DM patients at the end of 3 months, 6 months, 1 year, 2 years, 3 years, 4 years and 5 years of diagnosis and treatment were 1.9\%, 44.7\%, 52.8\%, 66.3\%, $69.2 \%, 70.2 \%$ and $70.5 \%$ respectively. The significant factors were age group and type of treatment regimen.

\section{Conclusions}

Achievement of optimal glycaemic control increases as the follow-up duration increases; it was only $1.9 \%$ at the third month and $70.5 \%$ at the fifth year of observation. Close to one third of patients $(29.5 \%)$ did not achieve target glucose even after five years and were at the verge of increased risk for diabetes related complications and death. Attention should be given to the time when patients achieve target glucoses level instead of just measuring the number of individuals who achieved glycaemic control in a short observation period.

\section{Background}

Diabetes is a complex, chronic illness that requires continuous medical care to reach target glycaemic level in order to prevent acute and chronic complications. Poorly managed diabetes leads to serious complications that include: loss of vision, kidney disease, nerve damage, peripheral circulatory disorders, 
stroke, heart disease and other complications, and premature death. Improving glycaemic control is a high priority in decreasing burden of diabetes and delaying complications [1, 2].

Diabetes is an important public health problem, one of the four priority non-communicable diseases (NCDs) targeted for action by world leaders in the 2011 Political Declaration on the Prevention and Control of NCDs, including cardiovascular diseases, cancers and chronic respiratory diseases. Both the number of cases and the prevalence of diabetes have been steadily increasing over the past few decades. The prevalence is growing most rapidly in low- and middle-income countries [3, 4]. According to IDF Diabetes Atlas 2017, in Ethiopia, prevalence of diabetes in adults was 5.2\%, total cases of adults with diabetes were 2,567,900, number of diabetes related deaths in adults was 30,972 , cost per person with diabetes was 551 USD and number of cases of diabetes in adults that are undiagnosed was 1,960,300. Ethiopia is also projected to have 14.1 million people with Impaired Glucose Tolerance (IGT) in the year 2045 which will make the country among the top ten countries worldwide $[5,6]$.

A systematic review of literatures conducted in low- and higher-income countries from 2011-2015 shows that glycaemic control is suboptimal in majority $(40 \%-60 \%)$ of people with diabetes. Therapeutic inertia appears to be an important contributor to poor glycaemic control in up to half of people with type2 diabetes, leaving these patients at increased and avoidable risk of serious complications[7]. Similarly, a systematic review of literatures among type 2 diabetes patients in Arabian Gulf council countries shows poor glycaemic control [8].

A study conducted in Uganda shows that $73.5 \%$ of the participants has suboptimal glycaemic control and metformin monotherapy and insulin therapy were found to be major predictors [9]. Similarly, a study conducted at Mathari national teaching hospital in Kenya shows that level of poor glycaemic control among Type 2 DM patients was $81.6 \%$ and being female, having high FBS and using drugs for other comorbid illness were factors significantly associated with poor glycaemic control [10].

Studies regarding diabetes control level have been conducted among different regions of Ethiopia. A study conducted in Suhul Hospital, Northwest Tigray, shows that level of poor glycaemic control was $63.5 \%$. Moderate physical exercise, taking meal prescribed by their physician appropriately and medication adherence were factors associated with good glycaemic control [11]. This study is consistent with studies reported from Yekatit 12 hospital (Addis Ababa) and Limmu Genet hospital, showing level of poor glycaemic control of $69.7 \%$ and $63.8 \%$ respectively $[12,13]$. In addition, a study conducted at Shana Gibe hospital among Type 2 DM patients shows that level of poor glycaemic control was $59.2 \%$ and significant factors were female sex, educational level, duration of diabetes treatment and adherence to follow up [14].

Similarly, a study conducted in Gondar shows that level of poor glycaemic control was $64.7 \%$ and significant predictors were being Type $1 \mathrm{DM}$ patient, being on insulin treatment and poor medication adherence. Also, a study conducted in Jimma shows that level of poor glycaemic control was $70.9 \%$ and being illiterate, farmer, taking combination of insulin and oral medication and poor medication adherence to be factors associated with poor glycaemic control $[15,16]$. A study conducted at Tikur Anbessa 
Specialized hospital among Type 2 DM patients attending diabetes clinic also shows high level of poor glycaemic control (80.0\%) and significant factors were longer duration of diabetes and being on insulin treatment [17].

Majority of these studies considered observation duration of 2-4 months and a few studies for about a year. But all of these studies measured glycaemic control for all patients together irrespective of the duration of diagnosis and initiation of treatment.

Diabetes is a chronic disease and as patients develop the disease at different times, they could also achieve optimal glycaemic control at different times. The time when they achieve target glucose level is an important component of follow up that predicts short and long term complications and death than just measuring magnitude of glycaemic control at one point in time [18]. Therefore, measurement of glycaemic control should be made in consideration of the time since diagnosis and initiation of treatment. Such kind of measurement will help clinicians to know if patients are achieving target in a reasonable amount of time or not.

In this study, we tried to address this issue by reviewing medical charts of newly diagnosed T2DM patients who received care within five years prior to the study with the aim of assessing achievement of optimal glycaemic control at different point in time and identifying associated factors among T2DM patients attending diabetes clinic of public teaching hospitals in Addis Ababa, Ethiopia.

\section{Methods}

\section{Study design, study area and period}

Hospital based observational retrospective chart review was conducted at two public teaching hospitals in Addis Ababa: St. Paul's Hospital Millennium Medical College (SPHMMC) and Yekatit 12 Hospital Medical College (Y12HMC) from May to July, 2018. During the study period, medical records of new Type 2 Diabetes Mellitus (T2DM) patients' who were on follow-up from January 1, 2013 to December 31, 2017 were reviewed. Both hospitals have diabetes clinics which are under the department of internal medicine.

\section{Study Population}

The study population was all selected new T2DM patients who were on follow up at diabetes clinic of public teaching hospitals in Addis Ababa from January 1, 2013 to December 31, 2017 who were over 18 years of age and not pregnant. According to data obtained from the HMIS reports of the hospitals, during this interval a total of 2,372 new patients were treated.

\section{Sample size determination and sampling procedure}

The sample size was determined using single population proportion formula by considering the following statistical assumptions: $95 \%$ confidence interval (Cl), 50\% proportion, $5 \%$ marginal error, design effect of 
2 for multi-stage sampling and a $20 \%$ non-response rate. With finite population correction, the final sample size for this study was 794 .

Multi-stage sampling technique was used to select medical charts for review. There were a total of 2,372 T2DM patients in Addis Ababa public teaching hospitals. Among the teaching hospitals, two were selected randomly. Then, 486 medical charts from St. Paul hospital and 308 medical charts from Yekatit 12 hospital were selected using simple random sampling with proportional allocation to the number of T2DM patients in each hospital.

\section{Operational Definitions}

\section{Optimal glycaemic control}

Optimal glycaemic control is defined as the three consecutive month average fasting blood glucose of 80-130 mg/dl with more or less stringent glycemic goals for individual patients based on age/ life expectancy, co-morbid conditions, advanced micro vascular complications, hypoglycemia unawareness, and individual patient considerations[19].

N.B: FBS is used as a follow up tool in our set up because HgA1c is not consistently available for patient diagnosis and follow up.

\section{Complexity of regimen}

[20]

\section{Complex}

taking at least 2 drugs, each with twice or more daily dosing

\section{Simple}

a regimen which is not complex

\section{Data Collection tools, procedures and quality assurance}

Data abstraction tool that consists of questions to assess: the socio-demographic characteristics, disease and medication related factors was developed by the principal investigator and used to collect the necessary data from patients' medical chart by trained data collectors.

The data abstraction tool was pretested for its completeness on $5 \%$ of randomly selected medical charts from the two hospitals that were not included in the study and necessary amendments on the tool was made.

\section{Data management and analysis}


The extracted data were coded, entered into Epi-Info version 7.2.1.0, cleaned, stored and exported to SPSS version 23.0 software for analysis. Categorical covariates were summarized using frequencies and percentages.. The association between the dependent variable and independent variables were analysed using Binary Logistic Regression. Univariate analysis was done at $25 \%$ level of significance to screen out independent variables used in the multiple Logistic regression model. The adequacy of the final model was assessed using the Hosmer and Lemeshow goodness of fit test and the final model fitted the data well $\left(x^{2}{ }_{(8)}=8.482\right.$ and $p$-value $\left.=0.388\right)$. For the Binary Logistic regression, $95 \%$ confidence interval for OR was calculated and variables with $p$-value $\leq 0.05$ were considered as statistically associated with level of glycaemic control.

\section{Result}

\section{Socio-demographic variables}

From the 794 samples, information was collected from 685 charts of T2DM patients making the response rate $86 \%$. Majority of the participants (27.7\%) were in the age range of $50-59$ years and $54.6 \%$ of the participants were females (Table 1).

Table 1

Socio-demographic characteristics among T2DM patients $(n=685)$

\begin{tabular}{|lll|}
\hline Variable & Frequency & Percent (\%) \\
\hline Age group in years & & \\
\hline $30-39$ & 154 & 22.5 \\
\hline $40-49$ & 163 & 23.8 \\
\hline $50-59$ & 190 & 27.7 \\
\hline $60-69$ & 122 & 17.8 \\
\hline$>=70$ & 56 & 8.2 \\
\hline Sex & & \\
\hline Female & 374 & 54.6 \\
\hline Male & 311 & 45.4 \\
\hline
\end{tabular}

\section{Diabetes related complications, diabetes hospitalization and medication related variables}

Close to one-third (32\%) of the participants had history of one or more complications. Majority of the participants had neuropathy (16.9\%) followed by acute complication (12.7\%), nephropathy $(5.1 \%)$ and 
other complications (3.8\%). Diabetes related hospitalization which was mainly due to acute complication was observed in $12.6 \%$ of the participants.

Majority of the participants, $63.9 \%$, were on oral anti-diabetic drug. Regarding complexity of treatment regimen, $70.8 \%$ were on simple regimen while $29.2 \%$ were on complex regimen (Table 2 ).

Table 2

Diabetes related complications, hospitalization and medication related variables among T2DM patients $(\mathrm{n}=685)$

\begin{tabular}{|c|c|c|c|}
\hline Variable & Frequency (\%) & Variable & Frequency (\%) \\
\hline \multicolumn{2}{|c|}{ History of diabetes related complication } & \multicolumn{2}{|c|}{ *Other complications } \\
\hline No & $466(68.0)$ & No & $659(96.2)$ \\
\hline Yes & $219(32.0)$ & Yes & $26(3.8)$ \\
\hline \multicolumn{2}{|c|}{ Acute complication } & \multicolumn{2}{|c|}{ More than one complication } \\
\hline No & 598 (87.3) & No & $644(94.0)$ \\
\hline Yes & $87(12.7)$ & Yes & $41(6.0)$ \\
\hline \multicolumn{2}{|c|}{ Diabetes nephropathy } & \multicolumn{2}{|c|}{ Diabetes related hospitalization } \\
\hline No & $650(94.9)$ & No & $599(87.4)$ \\
\hline Yes & $35(5.1)$ & Yes & $86(12.6)$ \\
\hline \multicolumn{2}{|c|}{ Diabetes neuropathy } & \multicolumn{2}{|l|}{ Regimen } \\
\hline No & $569(83.1)$ & Oral & $438(63.9)$ \\
\hline Yes & $116(16.9)$ & Insulin & $178(26.0)$ \\
\hline \multicolumn{2}{|c|}{ Complexity of regimen } & combination & $69(10.1)$ \\
\hline Simple & $485(70.8)$ & & \\
\hline Complex & $200(29.2)$ & & \\
\hline
\end{tabular}

\section{Others*: includes diabetes retinopathy, diabetic foot ulcer and diabetes gastropathy}

\section{Co- morbid illness related variables}

More than half (58.8\%) of the participants had history of co-morbid illness. Majority of the patients had hypertension (48.6\%) followed by dyslipidemia (22.6\%), cardiovascular disease (13.9\%) and other comorbid illness (11.1\%). More than one co-morbid illness was observed in $189(27.6 \%)$ of the participants (Table 3). 
Table 3

Co-morbid illness related variables among T2DM patients $(\mathrm{n}=$ 685)

\begin{tabular}{|c|c|c|c|}
\hline Variable & Frequency (\%) & Variable & Frequency (\%) \\
\hline \multicolumn{2}{|c|}{ History of co-morbid illness } & \multicolumn{2}{|c|}{ Cardiovascular disease } \\
\hline No & $282(41.2)$ & No & $590(86.1)$ \\
\hline Yes & $403(58.8)$ & Yes & $95(13.9)$ \\
\hline \multicolumn{2}{|c|}{ Hypertension } & \multicolumn{2}{|c|}{ * Other co-morbid illness } \\
\hline No & $352(51.4)$ & No & 609 (88.9) \\
\hline Yes & $333(48.6)$ & Yes & $76(11.1)$ \\
\hline \multicolumn{2}{|c|}{ Dyslipidemia } & \multicolumn{2}{|c|}{ More than one co morbid illness } \\
\hline No & $530(77.4)$ & No & $496(72.4)$ \\
\hline Yes & $155(22.6)$ & Yes & $189(27.6)$ \\
\hline
\end{tabular}

\section{Others*: includes renal disease, neurologic disease, chronic respiratory diseases and thyroid metabolism disorders Level of glycaemic control}

Among the 685 patients, only 483 (70.5\%) of the patients achieved optimal glycaemic control while 202 $(29.5 \%)$ of the patients did not achieve optimal glycaemic control during the five years observation period.

The number of patients who achieved optimal glycaemic control at the end of 3 months, 6 months, 1 year, 2 years, 3 years, 4 years and 5 years of diagnosis and treatment are $13(1.9 \%), 203(44.7 \%), 362$ (52.8\%), 454 (66.3\%), 474 (69.2\%), 481 (70.2\%) and 483 (70.5\%) respectively.

\section{Factors associated with level of glycaemic control}

From the univariate analysis, sex, age group, diabetes neuropathy, hypertension, dyslipidemia, cardiovascular disease, other co-morbid illness, more than one co-morbid illness, diabetes related hospitalization, treatment regimen and complexity of regimen were significantly associated with level of glycaemic control among T2DM patients at $25 \%$ level of significance.

However, only age group and treatment regimen were found to be significantly associated with level of glycaemic control in the multiple Logistic Regression model at $5 \%$ level of significance.

Accordingly, after adjusting for other covariates, compared to those in the age range of 30-39 years, the odds of achieving optimal glycaemic control among those in the age group 50-59, 60-69 and > = 70 
years were $53.3 \%, 60.5 \%$ and $75.9 \%$ less likely, respectively. On the other hand, patients in the age group of 40-49 years did not show significant difference compared to those in the age group of 30-39 years.

Patients who were on combination drug regimen were $50 \%$ less likely to achieve optimal glycaemic control compared to patients who were on oral treatment regimen (AOR $=0.500,95 \% \mathrm{Cl}: 0.270,0.927)$. On the other hand, patients who were taking insulin did not show significant difference compared to those who were taking oral regimen (Table 4). 
Table 4

Univariate and Multivariable analysis for factors associated with level of glycaemic control among T2DM patients $(\mathrm{n}=685)$

\begin{tabular}{|c|c|c|c|c|c|}
\hline \multirow[t]{2}{*}{ Variables } & \multicolumn{2}{|c|}{ Glycaemic control } & \multirow[t]{2}{*}{ COR(95\% Cl) } & \multirow[t]{2}{*}{ AOR(95\% Cl) } & \multirow{2}{*}{$\begin{array}{l}\mathrm{p}- \\
\text { value }\end{array}$} \\
\hline & Suboptimal & Optimal & & & \\
\hline \multicolumn{6}{|c|}{ Age group in years } \\
\hline $30-39$ & 24 & 130 & 1.00 & 1.00 & $0.010 *$ \\
\hline $40-49$ & 36 & 127 & $\begin{array}{l}0.651 \\
(0.368,1.153)\end{array}$ & $\begin{array}{l}0.663 \\
(0.359,1.226)\end{array}$ & \\
\hline $50-59$ & 62 & 128 & $\begin{array}{l}0.381 \\
(0.224,0.648)\end{array}$ & $\begin{array}{l}0.467 \\
(0.249,0.878)\end{array}$ & \\
\hline $60-69$ & 50 & 72 & $\begin{array}{l}0.266 \\
(0.151,0.468)\end{array}$ & $\begin{array}{l}0.395 \\
(0.199,0.784)\end{array}$ & \\
\hline$>=70$ & 30 & 26 & $\begin{array}{l}0.160(0.081 \\
0.317)\end{array}$ & $\begin{array}{l}0.241 \\
(0.106,0.547)\end{array}$ & \\
\hline \multicolumn{6}{|l|}{ Sex } \\
\hline Female & 99 & 275 & 1.00 & 1.00 & 0.351 \\
\hline Male & 103 & 208 & $\begin{array}{l}0.727 \\
(0.523,1.011)\end{array}$ & $\begin{array}{l}0.843 \\
(0.588,1.208)\end{array}$ & \\
\hline \multicolumn{6}{|c|}{ DM neuropathy } \\
\hline No & 145 & 424 & 1.00 & 1.00 & 0.069 \\
\hline Yes & 57 & 59 & $\begin{array}{l}0.354 \\
(0.235,0.533)\end{array}$ & $\begin{array}{l}0.647 \\
(0.404,1.035)\end{array}$ & \\
\hline \multicolumn{6}{|c|}{ Hypertension } \\
\hline No & 75 & 277 & 1.00 & 1.00 & 0.872 \\
\hline Yes & 127 & 206 & $\begin{array}{l}0.439 \\
(0.313,0.616)\end{array}$ & $\begin{array}{l}0.961 \\
(0.595,1.553)\end{array}$ & \\
\hline \multicolumn{6}{|c|}{ Dyslipidemia } \\
\hline No & 135 & 395 & 1.00 & 1.00 & 0.221 \\
\hline Yes & 67 & 88 & $\begin{array}{l}0.449 \\
(0.309,0.652)\end{array}$ & $\begin{array}{l}0.716 \\
(0.420,1.221)\end{array}$ & \\
\hline \multicolumn{6}{|l|}{ Cardiac } \\
\hline No & 152 & 438 & 1.00 & 1.00 & 0.106 \\
\hline
\end{tabular}

Note: COR, Crude odds ratio; AOR, Adjusted odds ratio; Cl, Confidence interval,* Statistically significant 


\begin{tabular}{|c|c|c|c|c|c|}
\hline \multirow[t]{2}{*}{ Variables } & \multicolumn{2}{|c|}{ Glycaemic control } & \multirow[t]{2}{*}{$\operatorname{COR}(95 \% \mathrm{Cl})$} & \multirow[t]{2}{*}{$\mathrm{AOR}(95 \% \mathrm{Cl})$} & \multirow{2}{*}{$\begin{array}{l}\mathrm{p}- \\
\text { value }\end{array}$} \\
\hline & Suboptimal & Optimal & & & \\
\hline Yes & 50 & 45 & $\begin{array}{l}0.312 \\
(0.201,0.486)\end{array}$ & $\begin{array}{l}0.601 \\
(0.324,1.114)\end{array}$ & \\
\hline \multicolumn{6}{|c|}{ Other co-morbid illness } \\
\hline No & 175 & 434 & 1.00 & 1.00 & \\
\hline Yes & 27 & 49 & $\begin{array}{l}0.732 \\
(0.443,1.208)\end{array}$ & $\begin{array}{l}1.051 \\
(0.555,1.990)\end{array}$ & 0.878 \\
\hline \multicolumn{6}{|c|}{$\begin{array}{l}\text { More than one co-morbid } \\
\text { illness }\end{array}$} \\
\hline No & 114 & 382 & 1.00 & 1.00 & 0.857 \\
\hline Yes & 88 & 101 & $0.343(0.240,0.448)$ & $\begin{array}{l}0.934(0.446 \\
1.957)\end{array}$ & \\
\hline \multicolumn{6}{|c|}{ Hospitalization } \\
\hline No & 170 & 429 & 1.00 & 1.00 & 0.184 \\
\hline Yes & 32 & 54 & $\begin{array}{l}0.669 \\
(0.417,1.072)\end{array}$ & $\begin{array}{l}0.670 \\
(0.372,1.209)\end{array}$ & \\
\hline \multicolumn{6}{|l|}{ Regimen } \\
\hline Oral & 113 & 325 & 1.00 & 1.00 & $0.033^{*}$ \\
\hline Insulin & 48 & 130 & $\begin{array}{l}0.942 \\
(0.635,1.397)\end{array}$ & $\begin{array}{l}0.668 \\
(0.407,1.097)\end{array}$ & \\
\hline Combination & 41 & 28 & $\begin{array}{l}0.237 \\
(0.140,0.402)\end{array}$ & $\begin{array}{l}0.500 \\
(0.270,0.927)\end{array}$ & \\
\hline \multicolumn{6}{|c|}{ Complexity of regimen } \\
\hline No & 111 & 374 & 1.00 & 1.00 & 0.080 \\
\hline Yes & 91 & 109 & $\begin{array}{l}0.355 \\
(0.251,0.504)\end{array}$ & $\begin{array}{l}0.659 \\
(0.413,1.051)\end{array}$ & \\
\hline
\end{tabular}

\section{Discussion}

The main purpose of this study was to assess achievement of optimal glycaemic control at different point in time and identify associated factors among T2DM patients in Addis Ababa public teaching hospitals. The study revealed that only $483(70.5 \%)$ of the patients achieved optimal glycaemic control while $202(29.5 \%)$ had failed to achieve optimal glycaemic control even after five years observation. The 
number of patients who achieved optimal glycaemic control at the end of 3 months, 6 months, 1 year, 2 years, 3 years, 4 years and 5 years of diagnosis and treatment were 13 (1.9\%), 203 (44.7\%), 362 (52.8\%), $454(66.3 \%), 474(69.2 \%), 481(70.2 \%)$ and 483 (70.5\%) respectively. It shows that the prevalence of glycaemic control increases as the follow-up duration increases, especially during the first year of diagnosis and treatment. Though patients have reached optimal glycaemic control at different time, the five years observation revealed that relatively majority of the patients reached optimal glycaemic control. This finding particularly the magnitude after one year of observation is in contrast to studies conducted in India, Uganda, Kenya, Suhul hospital, Yekatit 12 hospital, Tikur Anbessa Specialized hospital, Gondar and Jimma. This might be because of the relatively longer time given to observe the patients under study and the measurement of glycaemia level at different point in time.

Though the above number is bigger than previous studies, it shows that close to one third of patients who were on follow up for five years have not achieved optimal glycaemic control. Though setting a $100 \%$ goal for achieving optimal glycaemic control for all patients is not feasible, every diabetes care and management plan is to help almost every patient to reach the target glycaemic level in a reasonable amount of time.

Results obtained from this study regarding the identified associated factors are found to be analogous with literatures on the topic.

The age of patients was found to be an important factor that determines level of glycaemic control. The study shows that compared to those in the age range of 30-39 years, the odds of having good glycaemic control among those in the age group 50-59, 60-69 and $>=70$ years were $53.3 \%, 60.5 \%$ and $75.9 \%$ less likely, respectively. On the other hand level of glycaemic control does not show significant difference between those in the age group 30-39 and 40-49 years of age. This may be due to the fact that relatively younger patients (30-39 and 40-49) are thought to have less co-morbid illness and are more adherent to treatment and follow up which has a direct and indirect impact on diabetes disease progression and outcome. Therefore, this finding indicates that for patients 50 years and older, the likelihood of achieving optimal glycaemic control decreases with age. This finding is in line with studies conducted in Charleston, South Carolina and in India[21, 22].

The study found that type of treatment regimen is one of the significant factors that affects level of glycaemic control. Patients who were on combination drug regimen were $50 \%$ less likely to achieve optimal glycaemic control compared to patients who were on oral treatment regimen. On the other hand, patients who were taking insulin did not show significant difference compared to those who were taking oral regimen. This could be because taking a single type of regimen whether oral or insulin indirectly reflects that the patient's disease progression is relatively early and less aggressive that can be controlled with only a single regimen. On the other hand, those who were on combination therapy are those who have a more aggressive disease progression with possible short or long term complications or with the presence of other co-morbid illness that needs administration of more than one drug to control the disease which interferes with the attainment of target glucose level in a reasonable amount of time. It 
could also be because those patients who were on combination regimen are those who do not achieve optimal glycaemic control with a single regimen. That means those patients have stayed in suboptimal glycaemic control for long time that will expose them for increased risk of acute or chronic complications that in turn decreases the patients chance of achieving optimal glycaemic control. In addition, patients on combination therapy might be less adherent to medication because of the pill burden which poses a challenge in achieving optimal glycaemic control $[23,24]$. This result is in line with studies conducted in Gondar and Jimma $[15,16]$ while in contrast to a study conducted in Uganda [9]. The possible explanation for this difference might be due to differences in the method used to measure glycaemic control, the study areas and underlying population characteristics.

\section{Conclusion}

The considered five years observation time helped us to see the difference in the achievement of treatment target which varies with the time of diagnosis and initiation of treatment. The achievement of optimal glycaemic control increases as the follow-up duration increases and it was only $1.9 \%$ at the end of the third month and $70.5 \%$ at the end of the five years observation. Achievement of optimal glycaemic control at the end of five years observation was found to be relatively higher compared to reports from other studies but still almost half of the patients did not achieve treatment target after one year of followup and close to one third of patients who were on follow up for five years did not achieve optimal glycaemic control and were at the verge of increased risk for diabetes related complications and death.

Factors that affect level of glycaemic control were found to be age group and type of treatment regimen.

Therefore, attention should be given to the time when patients achieve target glucoses level, as it is an important indicator of risk of complication and death, instead of just measuring the number of individuals who achieved glycaemic control in a short observation period.

\section{Declarations}

\section{Ethics approval and consent to participate}

The study was conducted after ethical clearance was obtained from GAMBY Medical Sciences and Business College IRB, Addis Ababa Health Bureau, Y12HMC and SPHMMC. Medical record number was used for the data collection and personal identifiers were not included in the data extraction sheet. Access to the collected information was restricted to the principal investigator and confidentiality was maintained throughout the project.

\section{Consent for publication}

Not applicable 


\section{Availability of data and materials}

All relevant data are available within the manuscript.

\section{Competing interests}

The authors declare that they have no competing interests

\section{Funding}

This research did not receive any specific grant from funding agencies in the public, commercial, or notfor-profit sectors.

\section{Authors' contributions}

TWL conceived the idea, prepared the data extraction sheet, collected the data and drafted the manuscript. BTA supervised the study, contributed to the conception and revised the manuscript. Both coauthors read and approved the final draft.

\section{Acknowledgments}

The authors would like to thank Dr Sisay Sirgu (Endocrinologist, SPHMMC) for the professional advice given during the research work. We wish to thank the hospitals for their cooperation in accessing the HMIS reports and the medical charts of patients. We also would like to thank the supervisors and data collectors for their collaboration and great work during the data collection.

\section{References}

1. Kumar P, clark M. Kumar and Clark Clinical Medicine. 6th ed2014. 248 - 58 p.

2. Fauci A, Braunwald E, Kasper D. Harrison Principles of Internal Medicine. 18th ed. ed. New York: McGraw Hill Medical; 2015.

3. World Health Organization. Global Report on Diabetes 2016:16 - 8.

4. International Diabetes Federation. IDF Diabetes Atlas 2015:75-87.

5. International Diabetes Federation. IDF Diabetes Atlas 2017:43-86.

6. Ethiopian Diabetes Association. EDA 2016. Available from: http://www.diabetesethiopia.org.et/.

7. Blonde L, Aschner P, Bailey C, Ji L, Leiter L, Matthaei S. Gaps and barriers in the control of blood glucose in people with type 2 diabetes. Global Partnership for Effective Diabetes Management. 2017;14(3):172-83. 
8. Mohammed J, Afsana A, Sultana M, Mohammed A, Turky H, Hassan A, et al. Patient related Determinants of Glycamic control in people with Type 2 Diabetes in Gulf Cooperation Council Countries: A systematic review. Journal of Diabetes Research. 2016;2108:14.

9. Kibirige D, Akabwai GP, Kampiire L, Kiggundu DS, Lumu W. Frequency and predictors of suboptimal glycemic control in an African diabetic population. Int J Gen Med. 2017;10:33-8.

10. Ngoyo J, Karanja S, Njenga E, Muthami L. Factors associated with Glycaemic control among Type 2 Diabetes patients attending Mathari National Teaching Hospital, Nairobi Kenya. Journal of Endocrinology Diabetes. 2016;3(6):1-11.

11. Berhane F. Glycemic Control and it's Associated Factors in Type 2 Diabetic Patients in Suhul Hospital, Northwest Tigray, Ethiopia. Journal of Diabetes Metabolism. 2017;8:729.

12. Senait M, Fikre E, Workineh S. Assessment of glycaemic, lipid and blood pressure control among diabetic patients in Yekatit 12 Hospital, Addis Ababa, Ethiopia. Ethiopian Pharmaceutical Journal. 2015;31(2):131-40.

13. Bayisa B, Bekele M. Glycaemic control and asoociated factors among Type II diabetic patietns on chronic follow up at Southwest Ethiopia. Reserch and Reviews. 2017.

14. Daniel Y, Tigestu A. Glycaemic control and assocaited factors among Tyoe 2 Diabetic patients at Shanan Gibe hoapital, Southwest Ethiopia. BMC Res Notes. 2016;2017(10):(597).

15. Solomon M, Yemane B, Alemayehu W, Shitaye A, Nebiyu M. Level of sustained glycemic control and associated factors among patients with diabetes mellitus in Ethiopia: a hospital-based crosssectional study. Diabetes Metab Syndr Obes. 2015;8:65-71.

16. Tefera K, Tesfahun E, Hailay G. Factors associated with glycemic control among adult patients with type 2 diabetes mellitus: a cross-sectional survey in Ethiopia. BMC Res Notes. 2016;9:78.

17. Yohannes T, Adamu A, Tedla K, Wondimu A. Magnitude of glycaemic control and its associated factors among patients with type 2 diabetes at Tikur Anbessa Specialized Hospital, Addis Ababa, Ethiopia. PLoS One. 2018;13(3).

18. Leulseged TW, Ayele BT. Time to optimal glycaemic control and prognosticfactors among type 2 diabetes mellitus patients in public teaching hospitals in Addis Ababa, Ethiopia. PLoS ONE 2019;14(7).

19. ADA. Standards of Medical care in Diabtes, Glycaemic targets. 2017 ed2017.

20. Park KA, Kim JG, Kim BW, Kam S, Kim KY, Ha SW, et al. Factors that affect medication adherence in elderly patients with diabetes mellitus. Korean Diabetes J. 2010;34(1):55-65.

21. Ewenighi CO, Uchechukwu D, Adejumo BI. Responses to glycemic control therapy according to age, gender, level of adiposity, and duration of diabetes in type 2 diabetic patients. Indian J Med Sci. 2013;67(3-4):61-9.

22. Mulugeta G, Leonard E, Cheryl P, Carrae E, Yumin Z. Effect of Trajectories of Glycemic Control on Mortality in Type 2 Diabetes: A Semiparametric Joint Modeling Approach. Am J Epidemiol. 2010;171(10):1090-8. 
23. Nadia S, Sadia A, Naresh K, Waqar A, S F. DRUG NON-ADHERENCE, IN TYPE 2 DIABETES MELLITUS; PREDICTORS AND ASSOCIATIONS. J Ayub Med Coll Abbottabad. 2016;28(2):302-7.

24. Gebrehiwot T, Jemal H, Dawit T. Non adherence and associated factors among Type 2 diabetic patients at Jimma University specialized hospital, SW Ethiopia. J Med Sci. 2013;13q(7):578-84. 